\title{
PEMBUATAN PULP DARI DAUN PISANG
}

\author{
Dra. Hj. SURYANI, M.Si \\ Jurusan Kimia, Fakultas MIPA dan Ilmu Kesehatan, Universitas Muhammadiyah Riau \\ Jl. KH. Ahmad Dahlan No.88, Sukajadi Pekanbaru-28124 \\ Telp. (0761) 35008, 20497 Fax (0761) 36912 \\ e-mail: suryanimdiah@yahoo.com
}

\begin{abstract}
ABSTRAK
Proses yang digunakan dalm pembuatan pulp ini adalah proses semi kimia dengan menggunakan larutan pemasak $\mathrm{NaOH}$. Pembuatan pulp dilakukan pada pemasakan dengan temperatur $125^{\circ} \mathrm{C}$, dimana konsentrasi $\mathrm{NaOH}$ yang digunakan bervariasi dari 1\%, 1,3\%, 1,6\%, dengan waktu pemasakan 1 jam, 2 jam, 3 jam serta berat sampel tetap yaitu 250 gr. Data hasil percobaan menunjukkan bahwa kondisi pemasakan yang optimal diperoleh pada konsentrasi $\mathrm{NaOH}$ 1,6\% dengan lama pemasakan 3 jam dengan bilangan permanganat 5,833.
\end{abstract}

Kata Kunci: Pulp, $\mathrm{NaOH}$

\section{PENDAHULUAN}

Kebutuhan kertas yang meningkat dari tahun ke tahun, baik dari segi jumlah maupun dari mutu menjadi tantangan tersendiri bagi industri pulp. Industri pulp dan kertas merupakan salah satu padat modal yang mengalami cukup pesat dalam kurun waktu terakhir ini. Langkah strategis yang diambil pemerintah antara lain dengan menggunakan program pembangunan hutan taman industri (HTI) sebagai tumbuhtumbuhan utama pasokan bahan baku industri dimana mendatang. Namun demikian sampai saat ini keberhasilan program tersebut belum terlihat, karena pasokan bahan baku untuk industri pulp dan kertas belum dapat terpenuhi.

Tabel 1. Kebutuhan pulp di Indonesia

\begin{tabular}{|c|c|}
\hline Tahun & Jumlah (ton) \\
\hline 7995 & $1.120 .189,045$ \\
\hline 1994 & $1.378 .799,750$ \\
\hline 1995 & $1.853 .578,205$ \\
\hline 1996 & $2.134 .901,043$ \\
\hline 1997 & $2.372 .950,704$ \\
\hline
\end{tabular}

Sumber: Badan Pusat Statistik, Padang

Berdasarkan hal tersebut diatas, maka perlu kiranya dicari alternatif bahan baku lignoselulosa lainnya yang dapat menggantikan atau paling tidak menjadi bahan baku penunjang produksi pulp dan kertas yang dapat diperoleh dalam waktu yang singkat dan lebih mudah untuk dibudidayakan dalam skala besar.

Faktor yang mendasari pemikiran tentang pemanfaatan tumbuhan pisang sebagai bahan baku pulp dan kertas karena tumbuhan ini cukup mudah untuk dibudidayakan dalam waktu yang relatif singkat dibandingkan dengan HTI dan mempunyai kekuatan serat yang sangat tinggi sehingga dimungkinkan akan mampu menghasilkan pulp dan kertas dengan kekuatan yang tinggi, hal ini seperti dikemukakan oleh Atchison dan Me GoVern (1983) bahwa untuk memproduksi kertas dengan kualitas tinggi sampai saat ini masih menggunakan bahan baku serat yang berasal dari tanaman non kayu seperti: Rami, Kapas dan daun pisang.

Salah satu bahan non kayu yang digunakan untuk pembuatan kertas bermutu tinggi adalah daun pisang abaca. Karena tekstur seratnya yang cukup halus, maka; daun pisang tergolong komoditi yang cukup mahal dan digunakan sebagai bahan dasar 
uang kertas Dollar USA, Yen Jepang dan mata uang kertas dibanyak negara Eropa.

Saat ini, tanaman pisang yang ada di Indonesia komoditinya hanya terbatas pada buahnya saja. Meskipun jenis pisang yang ada di Indonesia bukanlah jenis pisang abaca yang ada di Eropa, dimana kandungan serat pada daunnya cukup sedikit jika dibandingkan dengan pisang yang ada di Eropa. Namun, nilai ekonomis dari daun pisang yang ada di Indonesia tetap dapat ditingkatkan melalui

pemanfaatan seratnya.

\section{METODOLOGI PENELITIAN}

\section{Peralatan dan Bahan}

1. Wadah 6. Gelas Piala dan gelas ukur

2. Wadah Pencuci 7. Pipet takar dan Pipet tetes

3. Mesin Penggiling 8. Biuret dan Erlenmayer

4. \% Plat Cetak 9. Blender

5. Pemanas 10. Timbangan

\section{Bahan}

1. Sampel ( Daun Pisang kering ) $\mathrm{Kmn} \mathrm{O}_{4} 0,1 \mathrm{~N}$

2. $\mathrm{NaOH}$ (Konsentrsi 1. 1,3 dan 1,6\%)

3. $\mathrm{H}_{2} \mathrm{O}$

4. $\mathrm{H}_{2} \mathrm{SO}_{4} 4 \mathrm{~N}$

5. $\mathrm{K}_{2} \mathrm{C}_{2} \mathrm{rO}_{7}$

6. $\mathrm{Na}_{2} \mathrm{~S}_{2} \mathrm{O}_{3}, 0,1 \mathrm{~N}$

7. KI $10 \%$

8. Larutan Kanji 0,2\%

\section{Persiapan Sampel}

Bahan yang digunakan berupa daun pisang kering. Daun pisang ini dipotongpotong sepanjang $4 \mathrm{~cm}$, kemudian ditimbang sebanyak 250gr dan dimasak dengan larutan Caustik soda $(\mathrm{NaOH})$.

\section{Pulping (Pembuburan)}

Daun pisang kering ditimbang sesuai yang dibutuhkan lalu dimasak dengan larutan $\mathrm{NaOH}$ dengan konsentrasi dan waktu yang bervariasi, selanjutnya daun yang telah dimasak dicuci dengan menggunakan air yang mengalir hingga bebas basa. Setelah itu daun pisang diblender sampai berbentuk bubur lalu dipres dengan mesin penggiling pada alat cetak lalu pulp dikeringkan.

Sebelum pulp dicetak dilakukan terlebih dahulu pemucatan (bleaching). Pulp yang di dapatkan berwarna cokelat diputihkan menggunakan zat pemutih hypo $\mathrm{NaOCl}$ (proses hypoclhorite bleaching). Pulp ini kemudian dicetak dan dikeringkan yang kemudian diuji bilangan permanganatnya.

\section{Standarisasi Larutan $\mathrm{Na}_{2} \mathrm{~S}_{2} \mathrm{O}_{3}$}

Kedalam erlenmayer $100 \mathrm{ml}$ dipipetkan secara kuantitatif $10 \mathrm{ml}$. larutan $\mathrm{K}_{2} \mathrm{Cr}_{2} \mathrm{O}_{7}$ 67,2 \% (B/V) lalu ditambahkan 5 ml larutan KI $10 \%$ dan larutan Kanji 0,2 \%. Campuran ini dititrasi dengan larutan $\mathrm{Na}_{2} \mathrm{~S}_{2} \mathrm{C}_{2} \mathrm{O}_{3}$ sampai warna biru berubah menjadi warna kuning gading.

N Na2S2O3 = mg K2Cr2O7 / ml Na2S2O3 x 49

\section{Penentuan Bilangan Permanganat}

Ditimbang $1 \mathrm{~g}$ contoh pulp yang telah dikeringkan. Kemudian tambahkan aquadest (700 ml) lalu diaduk dengan pengaduk listrik dalam beker gelas $1000 \mathrm{ml}$. setelah itu tambahkan $25 \mathrm{ml}$ larutan $\mathrm{H}_{2} \mathrm{SO}_{4} 4 \mathrm{~N}$ dan $\mathrm{KMnO}_{4} \quad 0,1 \quad \mathrm{~N}$ (secara kuantitatif), lalu dipanaskan pada suhu $70^{\circ} \mathrm{C}$ selama beberapa menit. Diamkan selama 5 menit dan tambahakan $10 \mathrm{ml} \mathrm{KI} \mathrm{10 \%} \mathrm{dan} \mathrm{beberapa}$ tetes kanji 0,2\%. Campuran segera dititrasi dengan larutan $\mathrm{Na}_{2} \mathrm{~S}_{2} \mathrm{O}_{3}$ yang dibutuhkan dicatat(A ml).

Prosedur yang sama juga dilakukan pada titrasi blanko (tanpa contoh pulp) dan volume $\mathrm{Na}_{2} \mathrm{~S}_{2} \mathrm{O}_{3}$ yang dibutuhkan dicatat (B $\mathrm{ml})$ 
Bilangan permangana dihitung sebagai:

$$
\mathrm{Bp}=\frac{(\mathrm{B}-\mathrm{A}) \cdot \mathrm{N} \times 10}{\mathrm{~S}}
$$

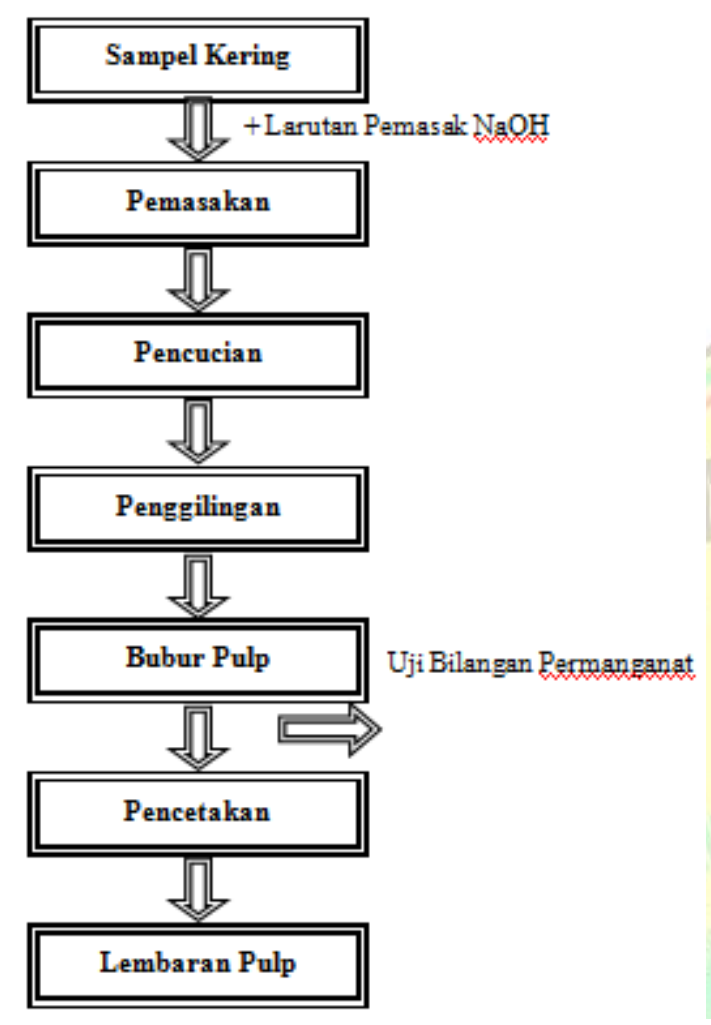

Gambar 1. Blok Diagram Pembuatan pulp Dari Daun Pisang

\section{HASIL DAN PEMBAHASAN}

Proses yang digunakan dalm pembuatan pulp ini adalah proses semi kimia dengan menggunakan larutan pemasak $\mathrm{NaOH}$. Proses ini dipilih karena dinilai sesuai untuk pembuatan pulp dari jenis tanaman non kayu. Pembuatan pulp dilakukan pada pemasakan dengan temperatur $125^{\circ} \mathrm{C}$, dimana konsentrasi $\mathrm{NaOH}$ yang digunakan bervariasi dari $1 \%, 1,3 \%, 1,6 \%$, dengan waktu pemasakan 1 jam, 2 jam, 3 jam serta berat sampel tetap yaitu 250 gr. Data hasil percobaan menunjukkan bahwa kondisi pemasakan yang optimal diperoleh pada konsentrasi $\mathrm{NaOH} 1,6 \%$ dengan lama pemasakan 3 jam.

\section{Pengaruh Konsentrasi larutan pemasak (NaOH) terhadap rendemen dan bilangan Permanganat}

Variabel yang diamati pada penelitian adalah penentuan pengaruh konsentrasi $\mathrm{NaOH}$ dan lama pemasakan terhadap persentase rendemen (persentase pulp) serta bilangan permanganat yang terdapat pada pulp. Hasil yang diperoleh hasil sebagai berikut:

Tabel 1 Hasil Pemasakan daun pisang kering, berat sampel 250 gram

\begin{tabular}{|c|c|c|c|c|c|c|}
\hline \multirow{3}{*}{$\begin{array}{c}\text { Konsentrasi } \\
\mathrm{NaOH}(\%)\end{array}$} & \multicolumn{3}{|c|}{ RENDEMEN (\%) } & \multicolumn{3}{|c|}{ BILANGAN PERMANGANAT } \\
\hline & \multicolumn{3}{|c|}{ Waktu Pemasakan (Jam) } & \multicolumn{3}{|c|}{ Waktu Pemasakan ( Jam ) } \\
\hline & $\mathbf{1}$ & 2 & 3 & $\mathbf{1}$ & 2 & 3 \\
\hline Sampel kering & Sampel & Sampel & Sampel & Sampel & Sampel & Sampel kering \\
\hline Sampel kering & Sampel & Sampel & Sampel & Sampel & Sampel & Sampel kering \\
\hline Sampel kering & Sampel & Sampel & Sampel & Sampel & Sampel & Sampel kering \\
\hline
\end{tabular}

\section{Rendemen Pulp}

Hubungan antara persentase Rendemen terhadap konsentrasi $\mathrm{NaOH}$ serta lama waktu pemasakan masing-masing dapat dilihat pada Tabel 1. Hubungan ini terlihat lebih jelas lagi pada gambar 1 dan 2. Pada kedua gambar ini dapat dilihat bahwa penurunan persentase rendemen relatif tajam pada kenaikan konsentrasi larutan pemasak $(\mathrm{NaOH})$. Rendemen terbanyak didapatkan pada waktu pemasakan 1 jam dengan konsentrasi $1 \%$. Dimana, bilangan 
permanganat yang didapatkan besar yaitu 15,47. Hal ini tidak memenuhi Standar Nasional Indonesia. Namun pada pemasakan 3 jam dengan konsentrasi 1,6\%, rendemen yang didapatkan kecil yaitu $46,16 \%$ dan bilangan permanganate yang didapatkan 5,833. Angka ini memenuhi Standar Nasional Indonesia (SNI 0494-1989.A). Hal ini menunjukkan semakin tinggi konsentrasi $\mathrm{NaOH}$, rendemen pulp yang didapatkan semakin kecil. Fungsi larutan $\mathrm{NaOH}$ pada pengolahan pulp ini adalah untuk menghidrolisis lignin yang terdapat dalam daun pisang. Semakin banyak lignin yang terurai, rendemen pulp yang didapatkan kecil. Semakin sedikit lignin yang terdapat dalam pulp maka mutu pulp yang dihasilkan semakin bagus. Hidrolisis lignin ini mulai

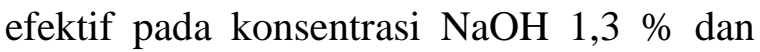
lame pemasakan 2 jam. Namun, pulp yang dihasilkan pada konsentrasi tersebut belum memenuhi SNI, dalam hal bilangan permanganate.

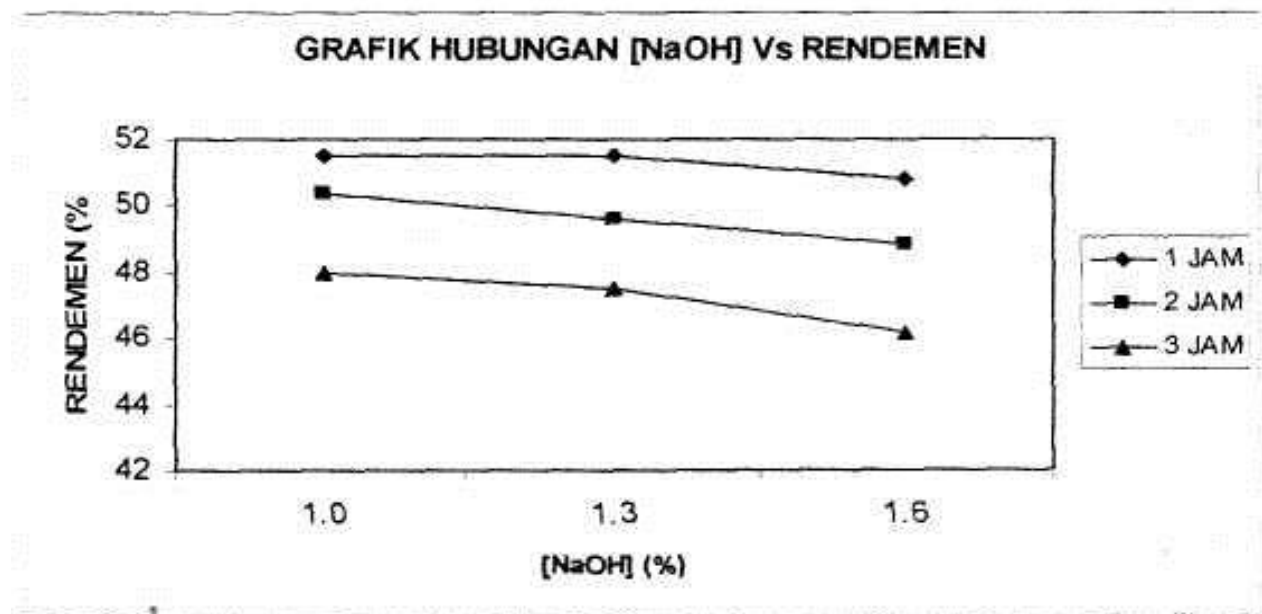

Gambar 2 Hubungan konsentrasi $\mathrm{NaOH}$ dengan Rendemen

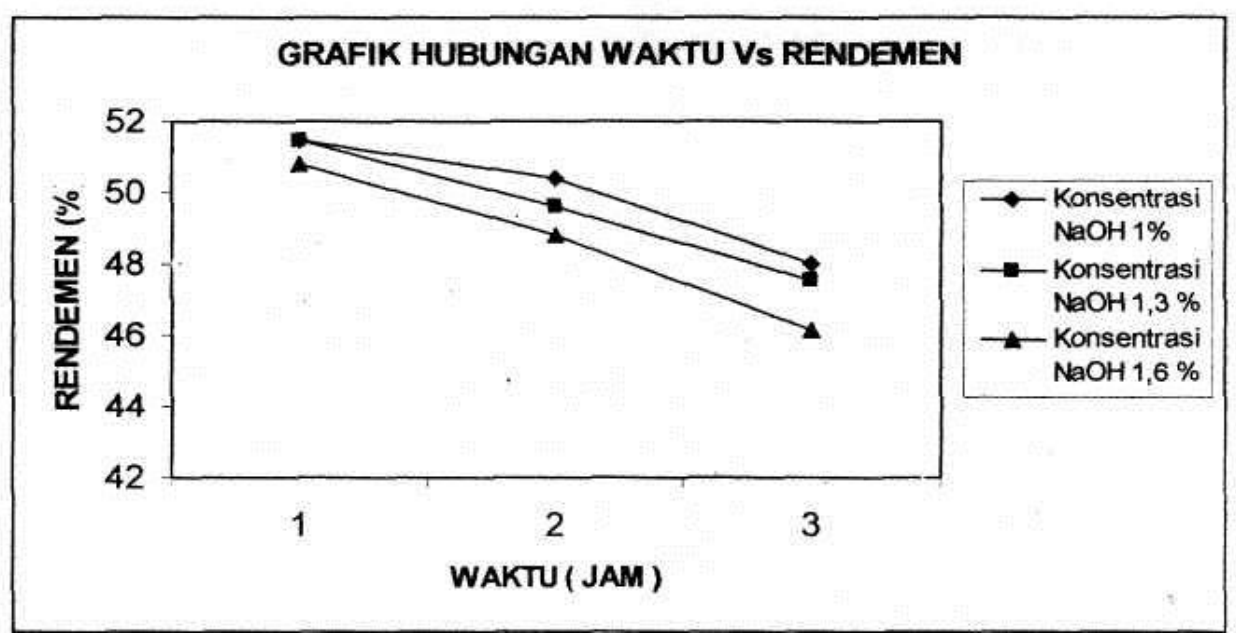

Gambar 3. Hubungan konsentrasi NaOH dengan Rendemen

\section{Bilangan Kappa}

Kualitas pulp dipengaruhi oleh kadar lignin yang terkandung dalam pulp itu sendiri. Pulp dengan kadar lignin rendah memiliki kualitas yang lebih baik. Kandungan lignin dalam pulp dapat 
ditentukan secara permanganometri dan dinyatakan sebagai bilangan permanganat.

Pengaruh $\mathrm{NaOH}$ dan lamanya waktu pemasakan dapat dilihat pada gambar 3. dan 4. Pada kedua gambar terlihat semakin besar konsentrasi serta lama waktu pemasakan, bilangan permanganat yang didapatkan semakin kecil. Hal ini dikarenakan pada temperatur $125^{\circ} \mathrm{C}$ air yang ada dalam bahan baku menguap dan diganti oleh $\mathrm{NaOH}$ hingga jenuh. $\mathrm{NaOH}$ jenuh ini akan menembus dinding serat dan mengenai lignin, sehingga serat terpisah dari ligninnya. Dan berakibat pada bilangan permanganat yang didapatkan semakin kecil. Bilangan permanganat ini menunjukkan kematangan dari suatu pulp. Semakin kecil bilangan permanganat akan semakin baik mutu pulp yang dihasilkan. Karena sebagian besar lignin yang terdapat dalam daun pisang kering telah bereaksi dengan larutan pemasak $(\mathrm{NaOH})$ membentuk natrium lignat yang larut dalam air dan terpisah dari selulosa. Bilangan permanganat terkecil diperoleh pada konsentrasi $\mathrm{NaOH} \quad 1,6 \%$ dan waktu pemasakan 3 jam yaitu 5,833. Angka ini telah memenuhi SNI (Standar Nasional Indonesia) terhadap bilangan permanganate yaitu 6,8 sesudah pemucatan dan 15,5 sebelum pemucatan.

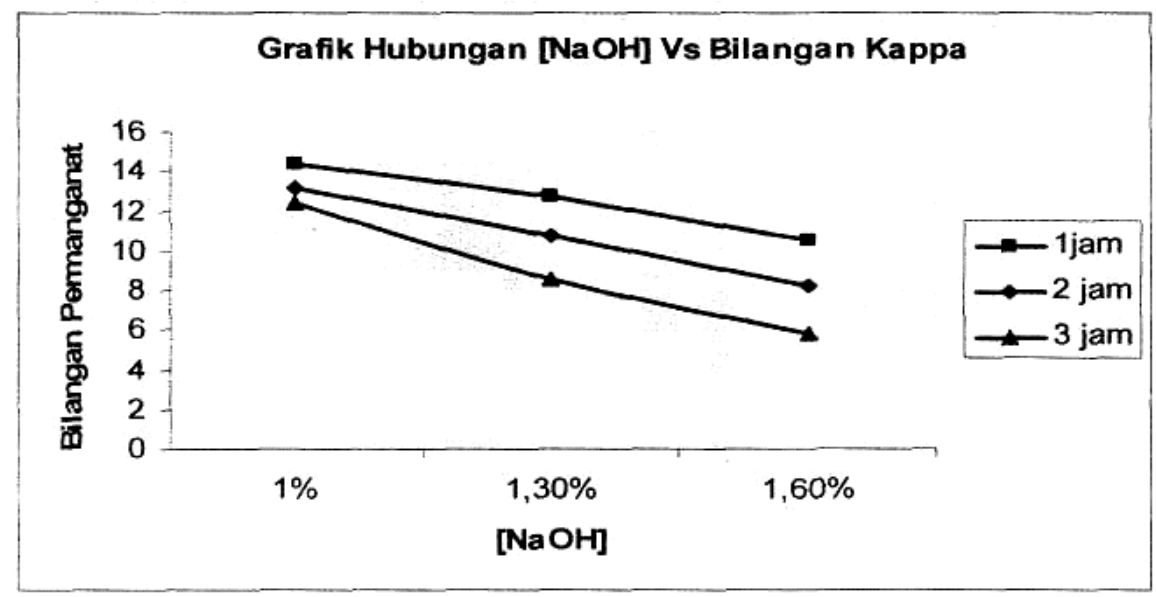

Gambar 4 Hubungan Konsentrasi NaOH Dengan Bilangan Kappa

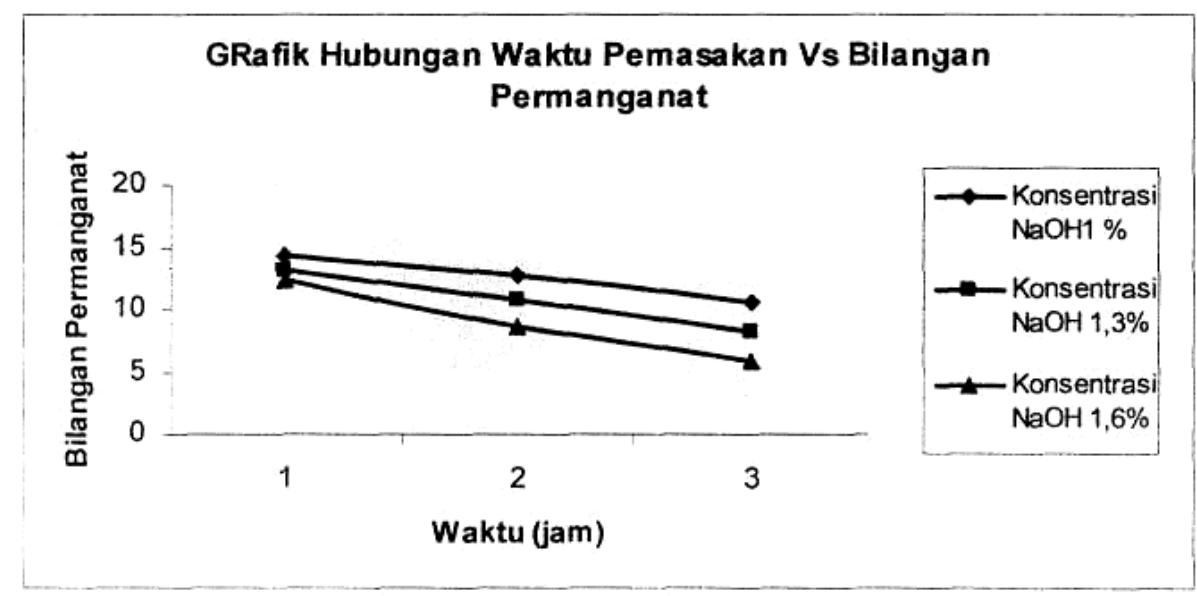

Gambar 5 Hubungan waktu pemasakan Dengan Bilangan permanganate 


\section{KESIMPULAN}

Dari penelitian yang telah dilakukan dapat diambil kesimpulan sebagai berikut:

1. Pembuatan pulp dari daun pisang kering dapat dilakukan dengan proses semi kimia dengan $\mathrm{NaOH}$ (caustik soda) sebagai larutan pemasak.

2. Rendemen pulp yang dihasilkan dipengaruhi oleh konsentrasi larutan pemasak $\mathrm{NaOH}$ serta lamanya waktu pemasakan

3. Pulp yang memenuhi standar (SNI 04941989.A, yaitu 6,8 setelah pemucatan dan 15,5 sebelum pemucatan) didapatkan pada konsentrasi larutan pemasak $(\mathrm{NaOH})$ 1,6 \% dengan waktu pemasakan 3 jam dengan bilangan permanganat 5,833

\section{DAFTAR PUSTAKA}

Filser and filser, 'Text Book of Organik

Chemistry', Maruzen 1950

Kasim, M, 'Proses Pembuatan Pulp'. Balai penelitian dan pengembangan Industri Padang, 2000.

Muadjim, Drs.Bsc, 'Teknologi Pengolahan Pisang'. PT. Gramedia, Jakarta, 1996

Mariani, Pembuatan Pulp dan Kertas dengan bahan baku Rosela', Lembaga Penelitian Selulosa, Bandimg, 1983

Mac Donald G.R and Franklin, Nj, Pulp and Paper Manufakture', $2^{\text {nd }}$ ed, vol $2 \mathrm{Me}$ Graw-Hill Book Company, New york, 1969

Rismunandar, " Bertanam Pisang " Penerbit Sinar Baru, Bandung, 1998 